\title{
Experiência com gamificação: Uma abordagem aplicada no ambiente virtual de aprendizagem Moodle
}

\author{
Thiago M. Silva ${ }^{1}$, Leonardo S. Soares ${ }^{2}$, Katyeudo Karlos de S. Oliveira ${ }^{1}$, Rafael S. \\ Barbosa $^{1}$, Higor Ricardo M. Santos ${ }^{2}$, Gabriel A. de Albuquerque Júnior ${ }^{1}$ \\ ${ }^{1}$ Programa de Pós-Graduação em Informática Aplicada (PPGIA) \\ Universidade Federal Rural de Pernambuco (UFRPE) \\ Rua Dom Manoel de Medeiros, s/n, Dois Irmãos, CEP 52171-900, Recife - PE - Brasil \\ ${ }^{2}$ Universidade de Pernambuco, Campus Garanhuns (UPE) \\ CEP 55.294-902 - Garanhuns - PE - Brasil \\ \{tmartiiins, leonardo.sooares, karlos.1914.so, \\ s.rafaelbarbos, higormonteiro1206, gaaj1980\}@gmail.com
}

\begin{abstract}
This article resumes research on gamification at some educational time, analyzing the impact of gamification in a Virtual Learning Environment (VLE). The main goal was to investigate the benefits and challenges of gamification strategies in order to measure students engagement in learning. In the research was developed a workshop that has 5 phases of exercises that approach the gamification itself as object of study, using its own methods, causing a metalinguistic function that is self-explanatory. In the results of the research were presented some relevant data on the behaviors that the gamification caused in the individuals who participated in the workshop.
\end{abstract}

Resumo. Este artigo resume o aprofundamento de uma pesquisa no âmbito educacional, analisando o impacto da gamificação atrelada a um Ambiente Virtual de Aprendizagem (AVA). Teve como objetivo geral, investigar os benefícios e desafios das estratégias de gamificação, visando medir o engajamento de estudantes pelo aprendizado. Foi desenvolvida uma oficina dividida em 5 fases de exercícios que abordam a própria gamificação como objeto de estudo, utilizando seus próprios métodos, causando uma função metalinguística que é autoexplicativa. Nos resultados da pesquisa foram apresentados alguns dados relevantes sobre os comportamentos que a gamificação causou nos indivíduos que participaram da oficina.

\section{Introdução}

Com a popularização dos computadores e smartphones, o uso da internet passou a ser acessível e indispensável para a comunicação da sociedade moderna, podendo ser utilizada em qualquer lugar, através de serviços fornecidos por operadoras telefônicas e de internet. De acordo com uma matéria de Demartini (2018) publicada no portal CanalTech, oficialmente no Brasil, há mais smartphones ativos do que pessoas. A Fundação Getúlio Vargas revelou em sua nova edição de sua pesquisa anual sobre uso de tecnologia, que hoje são 220 milhões de celulares em funcionamento no país contra 207,6 milhões de habitantes, de acordo com os dados mais recentes do IBGE (Instituto Brasileiro de Geografia e Estatística). 
VIII Congresso Brasileiro de Informática na Educação (CBIE 2019)

Anais do XXV Workshop de Informática na Escola (WIE 2019)

Desta forma, a internet se torna uma popular fonte de informações onde é possível ter acesso a conteúdos de qualquer assunto a todo instante, permitindo aos usuários a criação de conhecimento fora do ambiente escolar. No cenário atual da educação, é primordial que estudantes tenham acesso às tecnologias digitais com intuito de buscar por informações que auxiliem o processo ensino-aprendizado, quebrando um paradigma sociocultural que implica em mudanças educacionais [Martins e Giraffa 2015]. Além disto, para os estudantes da nova geração, o elemento "diversão" é natural para o seu cotidiano, e nas suas aprendizagens não é diferente [Martins e Giraffa 2015].

Um dos grandes desafios para educadores, segundo Moran (2000), é fazer com que a informação se torne significativa, escolhendo as informações verdadeiramente importantes entre tantas possibilidades e compreendê-las de forma cada vez mais abrangente e profunda. Métodos ainda em curso na atualidade, que são baseados principalmente na transmissão (do educador) e memorização (do educando), precisam ser substituídos por estratégias capazes de comunicar e que estimulem novos modos de modificar, produzir, compartilhar e aprender [Netto 2014].

A gamificação, gamification ou ludificação, segundo Vianna et al. (2013, p.13) "corresponde ao uso de mecanismos de jogos orientados ao objetivo de resolver problemas práticos ou de despertar engajamento entre um público específico". Cada vez mais, esse conjunto de técnicas tem sido aplicado por empresas e entidades educacionais como alternativas às abordagens tradicionais. Ela pode ser uma aliada primordial na educação como estratégia de ensino-aprendizagem, tendo resultados muito interessantes e positivos obtidos com estas experiências, visto que o público-alvo faz parte de uma geração familiarizada com jogos [Sheldon 2012].

Este artigo resume o aprofundamento da pesquisa de gamificação no âmbito educacional, analisando o impacto da gamificação atrelada a um Ambiente Virtual de Aprendizagem (AVA) durante a realização de uma oficina com estudantes de ensino superior e técnico. O material apresentado na oficina explica a própria gamificação e seus elementos, trazendo uma função metalinguística, que é autoexplicativa. Acreditava-se que a aplicação dela no contexto educacional poderia enriquecer o processo de engajamento e favorecer o melhor aprendizado do estudante em suas atividades. Refletindo sobre as contribuições que métodos de jogos têm para o engajamento do estudo, esperava-se que a pesquisa fosse pertinente, pois visa a aplicação destes métodos de jogos para auxiliar o exercício de práticas docentes, no intuito de verificar o impacto que este suporte educativo causa na aprendizagem.

O trabalho está organizado da seguinte forma: a Seção 2 mostra os trabalhos relacionados. Na Seção 3 apresenta a teoria acerca de Gamificação e Moodle. A Seção 4 aborda o Desenvolvimento da Oficina na Plataforma Moodle. Na Seção 5, é apresentado os resultados do estudo. Finalmente, a Seção 6 apresenta a conclusão e trabalhos futuros.

\section{Trabalhos Relacionados}

Foram encontrados na literatura alguns trabalhos que abordam o tema deste trabalho, dentre eles, destacam-se os seguintes.

Visando analisar a efetividade do uso de mecânicas de gamificação sobre o engajamento de alunos no ensino fundamental, Seixas et al. (2014) desenvolveram uma pesquisa com 61 alunos de duas turmas do $9^{\circ}$ ano do Ensino Fundamental. Ao avaliar o perfil dos estudantes, os autores identificaram que $95,8 \%$ possuíam computador, e destes, 
VIII Congresso Brasileiro de Informática na Educação (CBIE 2019)

Anais do XXV Workshop de Informática na Escola (WIE 2019)

89,5\% utilizam essa ferramenta para estudar. Grande parte destes alunos fica em média até 4 horas acessando a internet para fins de redes sociais (Facebook, Instagram, Twitter, entre outros), Sites de Entretenimento (Youtube, blogs de humor, entre outros) e Conteúdos educativos (que auxiliem as tarefas escolares), em ordem de preferência.

Duas ferramentas que utilizam estratégias de gamificação foram utilizadas para o desenvolvimento da pesquisa, sendo elas: ClassDojo - plataforma gratuita e online cuja proposta é recompensar o comportamento de estudantes, incentivando comportamentos positivos específicos como persistência, curiosidade e trabalho em equipe. E, ClassBadges - ferramenta gratuita pela qual os professores podem premiar as habilidades de seus alunos e/ou domínio acadêmico, além possuir uma curva de aprendizado baixa.

Inicialmente, Seixas et al. (2014) afirmaram que os alunos mostraram-se comprometidos com a realização de suas atividades, porém, estes queriam ser reconhecidos por isso.

Com a funcionalidade "Bloco" no Ambiente Moodle, Roque et al. (2013) desenvolveram uma pesquisa de natureza tecnológica para gerar um produto de software. Assim, foi criado no Moodle o curso de "Arquitetura de Computadores" que contemplou um conteúdo pedagógico básico para a competição, com questões de múltipla escolha para três níveis diferentes, já contemplando a característica de gamificação.

Segundo Roque et al. (2013), os testes foram realizados com acesso em computador pessoal. Assim, todas as atividades introduzidas dentro do curso de Arquitetura de Computadores (criado para testes no Moodle) apresentaram bons resultados, conforme as características de competição/gamificação introduzidas. Assim, os autores concluíram que todas as tentativas de respostas dos questionários não apresentaram problemas durantes os testes. Finalmente, pode-se concluir que a plataforma Moodle oferece um suporte confiável as metodologias de gamificação.

Este trabalho teve como diferencial, agregar as metodologias adotadas pelos dois trabalhos apresentados, como o sistema de recompensa de emblemas, barra de progresso, entre outros, em uma oficina online desenvolvida na plataforma Moodle.

\section{Gamificação e Moodle}

Em linhas gerais, a gamificação é uma metodologia onde mecanismos de jogos, como premiações, competições e pontos, são utilizados em ambientes fora de contexto de jogos e possuem objetivos educacionais, permitindo engajar, sociabilizar, motivar e ensinar de maneira mais eficiente [Vianna et al. 2013]. Nos últimos anos principalmente, game designers de diversas partes do mundo têm se dedicado a aplicar princípios de jogos em campos variados, tais como saúde, educação, políticas públicas, esportes ou aumento de produtividade [Vianna et al. 2013].

Para Fogg (2009) a gamificação oferece ferramentas adequadas para gerar uma mudança positiva no comportamento do aluno, que criam aplicações mais eficazes e envolventes para a aprendizagem a distância. Os benefícios dela têm um potencial que podem tratar questões bem conhecidas como a falta de motivação dos alunos, devido à capacidade limitada de interação com o professor e colegas de classe [Liaw 2008].

Ambiente Virtual de Aprendizagem (AVA), ou do inglês, Learning Management System (LMS), visa simplificar a administração de cursos. Esse ambiente auxilia os alunos no planejamento individual de seus processos de aprendizagem e permite que eles 
VIII Congresso Brasileiro de Informática na Educação (CBIE 2019)

Anais do XXV Workshop de Informática na Escola (WIE 2019)

colaborem entre si por intermédio da troca de informações e conhecimentos. Segundo Pereira et al. (2007, p.4) "em termos conceituais, os AVAs consistem em mídias que utilizam o ciberespaço para veicular conteúdos e permitir interação entre os atores do processo educativo". Por conta destas características, os AVAs se tornaram amplamente utilizados em cursos de Educação à Distância (EAD).

Para o desenvolvimento da oficina realizada para esta pesquisa, foi escolhida a plataforma Moodle, pelo maior grau de afinidade e experiência do pesquisador. O Moodle é baseado na web, podendo ser acessado de qualquer lugar do mundo. Esta plataforma possui uma interface padrão compatível com dispositivos móveis e desktop. O conteúdo nele contido é facilmente acessível e consistente em diferentes navegadores da web. A plataforma ainda fornece o conjunto de ferramentas flexíveis para suportar o aprendizado misto e os cursos $100 \%$ online. É possível também, configurar de maneira personalizada, recursos que integram tudo o que é necessário para um curso usando uma gama completa de recursos integrados, incluindo ferramentas colaborativas externas, como fóruns, wikis, bate-papos e blogs [Moodle.org 2019].

\section{Desenvolvimento da Oficina na Plataforma Moodle}

A oficina de gamificação foi desenvolvida na plataforma Moodle, que é uma plataforma de aprendizado projetada para fornecer a educadores, administradores e alunos um sistema robusto, seguro e integrado para criar ambientes de aprendizado personalizados [Moodle.org 2019]. Ela pode ser usada de forma gratuita em um servidor web pessoal e também pode ser utilizada através de servidores online gratuitos ou pagos. O Moodle é liderado e coordenado pelo Moodle HQ, que é apoiado financeiramente por uma rede de mais de 80 empresas de serviços Moodle Partner em todo o mundo.

Para poder utilizar esta plataforma, é necessário baixar e tê-la instalada em um servidor local ou um servidor online, além de possuir um usuário de acesso para fazer as configurações iniciais. Desta forma, para implementar a oficina gamificada deste projeto na plataforma, foi preciso que o ambiente fosse instalado em um servidor online, pois seria possível ser acessado em qualquer momento. Uma das alternativas encontradas, foi a do grupo Gnomio. O grupo é formado por fãs do Moodle que oferecem ferramentas e servidores gratuitos para a comunidade de e-learning. Em seu domínio existe a possibilidade de ter sua sala de aula virtual ativa, com seu próprio subdomínio, acesso HTTPS seguro em todo o site, privilégios de administração completos, sem limitações no número de cursos, usuários ou espaço em disco e totalmente gratuitos [Gnomio.com 2019]. Por ser um serviço gratuito, existe a presença de propagandas nos subdomínios, que geram receita para o grupo.

O subdomínio disponível selecionado para o projeto foi o "www.cursogamificacao.gnomio.com". Antes de começar a implementar a oficina foi necessário customizar o layout do ambiente, pois a aparência padrão era muito "simples" e sem cor, deixando de ser algo atrativo. Nas configurações de administração do ambiente, na aba "Aparência" e "Seletor de tema", foi selecionado um layout mais atrativo e colorido. O tema selecionado foi o intitulado "Campus". A Figura 1 ilustra a página inicial do ambiente com o tema já selecionado. 
VIII Congresso Brasileiro de Informática na Educação (CBIE 2019)

Anais do XXV Workshop de Informática na Escola (WIE 2019)

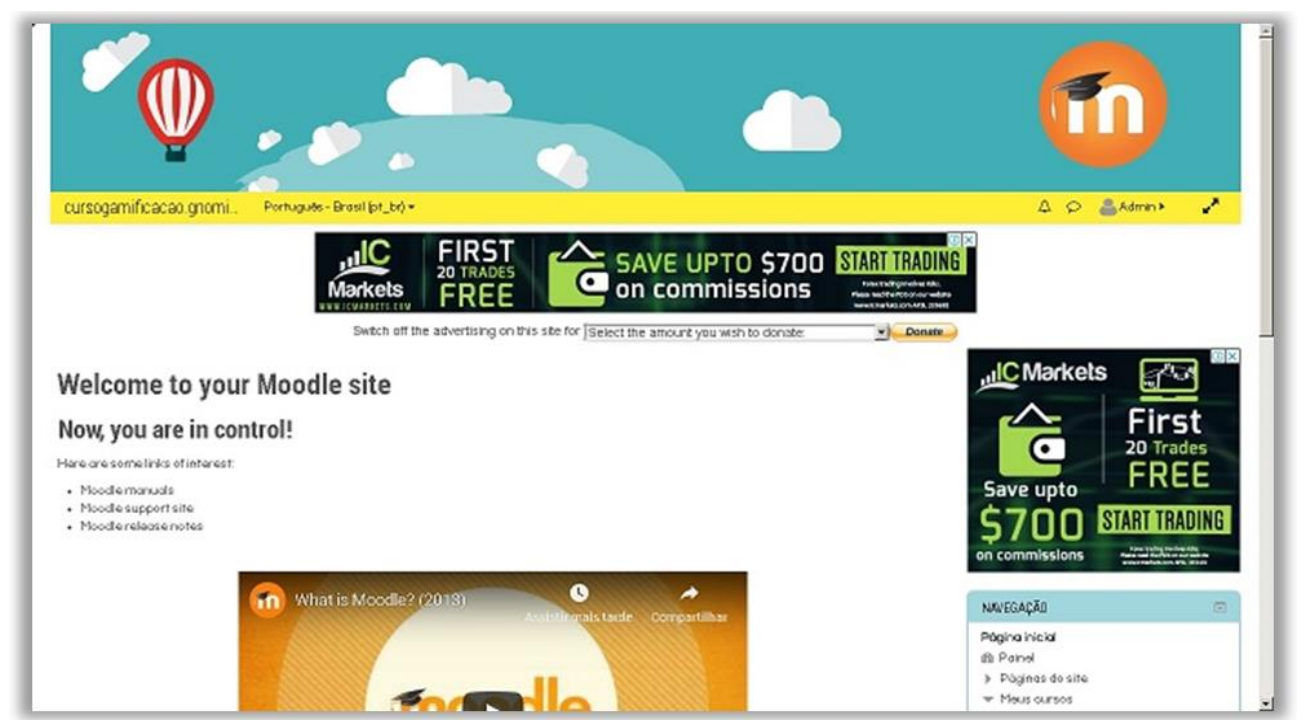

Figura 1. Tema Campus

Após as configurações do layout foi iniciado o desenvolvimento da oficina. Primeiramente foram feitas pesquisas sobre cursos que utilizavam gamificação na sua estrutura, para consequentemente adotar uma abordagem. A abordagem escolhida para o ambiente foi o da professora $\operatorname{Dr}^{\mathrm{a}}$. Cristiane Mendes Netto (2015), que é exemplificada em algumas de suas videoaulas disponibilizadas no YouTube. Baseando-se nessa abordagem, foram desenvolvidas 5 fases onde cada uma delas iria conter atividades a serem resolvidas pelos participantes, sendo a primeira fase com duas atividades. Os participantes só poderiam passar de fase após concluir as atividades da fase anterior. Além disso, também foram ativados alguns itens da funcionalidade "Bloco" e "Emblemas" já existentes do domínio Gnomio. São eles, o bloco da "barra de progresso", o bloco "últimos emblemas" e alguns ícones de emblemas disponibilizados dentro da biblioteca de imagens do domínio.

A primeira fase intitulada "Fase 1 - Apresentação dos Participantes" é composta por duas atividades. Na primeira atividade ("Atividade 1 - Apresentação dos participantes") foi feita uma introdução aos participantes onde eles puderam se apresentar informando seu nome, o curso (graduação, técnico, pós-graduação) em que estudava e a instituição. A segunda atividade ("Atividade 2 - Qual a sua experiência/domínio com plataformas de Ensino a Distância (EAD)?”), consiste em dar um feedback sobre o nível de experiência que o participante tinha até aquele momento, em plataformas EAD, selecionando uma opção de múltipla escolha contendo as opções "Nenhuma", "Baixa", "Intermediária" e "Experiente". Ao completar cada uma das atividades, o participante ganhava uma medalha "Sociável" e "Feedback" respectivamente. Na Figura 2 é demonstrado as medalhas que os participantes ganhavam ao concluir cada atividade.

Na segunda fase ("Fase 2 - Conceito de Gamificação"), a atividade ("Atividade 3 - Uma breve explicação do conceito de gamificação") consistiu em fazer uma breve leitura sobre o conceito de gamificação, juntamente com a análise de uma entrevista publicada em 2013 no canal do YouTube "Salaoficial", com o professor Luciano Meira, considerado um dos pioneiros da gamificação no Brasil. Nesta fase não houve recompensa de medalha, pois ela está associada com a fase posterior. 
VIII Congresso Brasileiro de Informática na Educação (CBIE 2019)

Anais do XXV Workshop de Informática na Escola (WIE 2019)

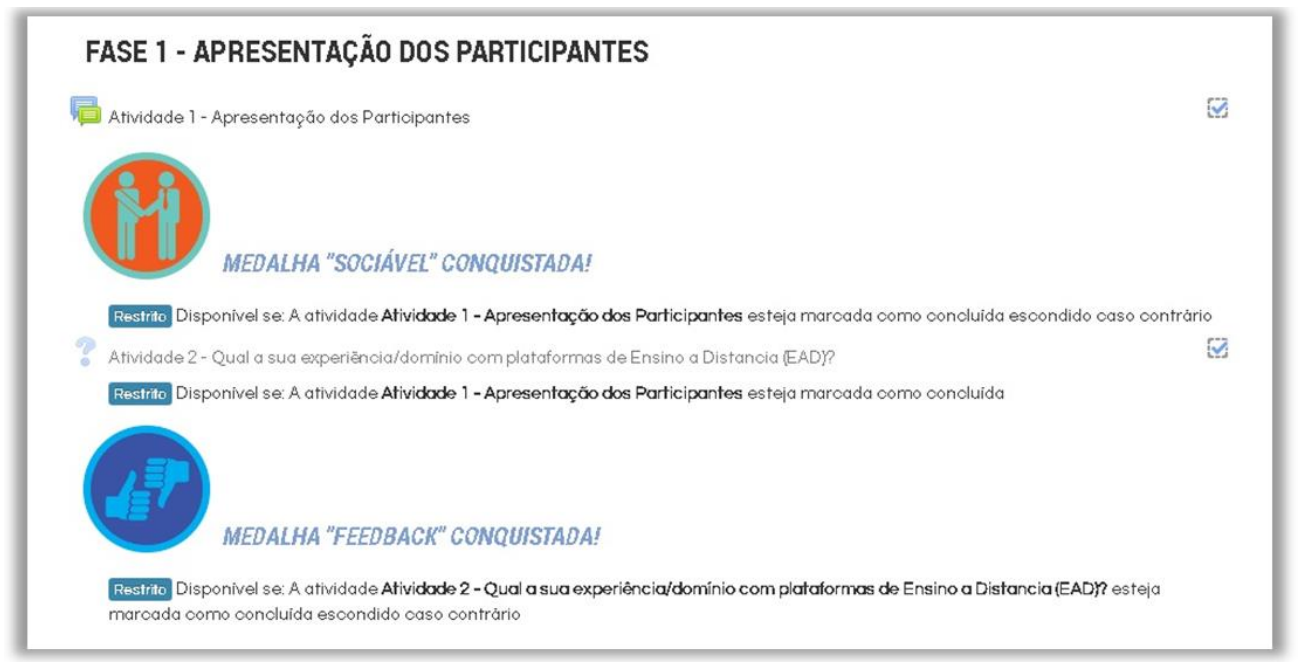

Figura 2. Medalhas

A terceira fase ("Fase 3 - Elementos de Gamificação") possuía um exercício de leitura que apresentava um infográfico mostrando 10 elementos da gamificação para o engajamento de equipes e empresas. O infográfico foi produzido e disponibilizado no site da empresa Oniria, que possui soluções baseadas em gamificação. Após a conclusão desta atividade o participante ganha a medalha "Um Bom Leitor".

$\mathrm{Na}$ quarta fase ("Fase 4 - Recursos do Moodle") foi desenvolvido um exercício projetado no software Hot Potatoes, que permite que você crie exercícios interativos de múltipla escolha, de resposta curta e de palavras cruzadas. O tipo escolhido foi o de palavras cruzadas que é demonstrada na Figura 3, onde 5 palavras ditas e explicadas nas atividades anteriores foram escolhidas como respostas.

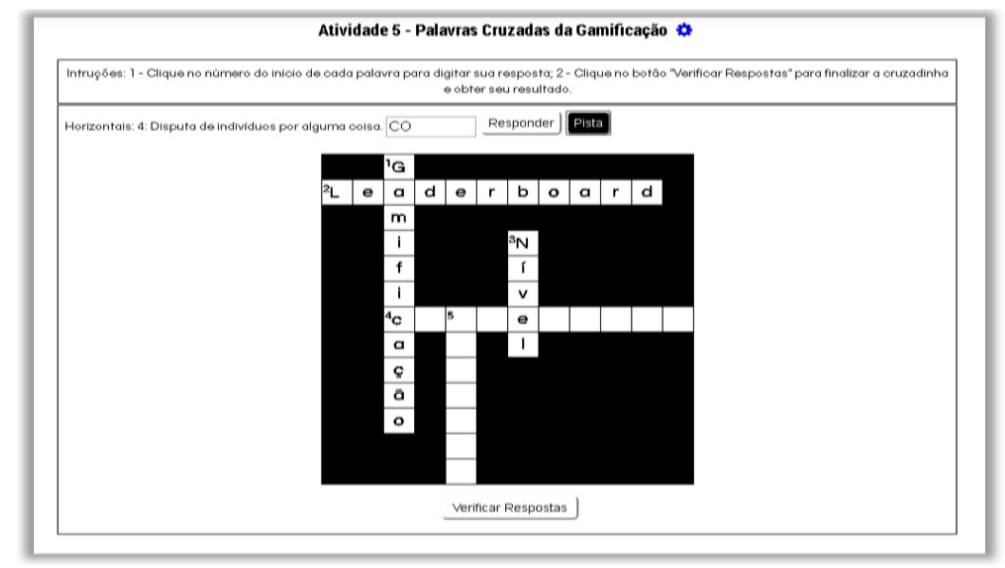

Figura 3. Palavras Cruzadas da Gamificação

Como ilustrado na Figura 3 a "Atividade 5 - Palavras Cruzadas da Gamificação", quando o participante clica no botão "Pista", a barra de resposta é preenchida com as duas letras iniciais da palavra em questão. Ao concluir esta atividade o participante recebe a medalha "Rei das Palavras Cruzadas", além da porcentagem de acerto das palavras.

Por fim, na "Fase 5 - Conclusão" os participantes responderam um questionário a fim de receber o feedback de como se comportaram durante a participação da oficina e receberam a medalha "Conclusão". 
VIII Congresso Brasileiro de Informática na Educação (CBIE 2019)

Anais do XXV Workshop de Informática na Escola (WIE 2019)

\section{Resultados}

Visando obter feedbacks sobre o hábito de jogar dos participantes e da experiência com a oficina Gamificação com Moodle, foi elaborado um questionário com 12 perguntas através da ferramenta Google Formulários, com questões abertas e questões de múltipla escolha, ambas com respostas obrigatórias e opcionais.

Participaram da oficina 14 estudantes com idades entre 17 e 26 anos. Os participantes foram selecionados com base na condição de estarem em algum curso, seja de graduação, técnico ou pós-graduação para que os resultados pudessem ser analisados juntos com a literatura. Os convites para a participação da oficina foram feitos através de uma rede social para 30 pessoas, porém 16 apresentaram resistência em participar. Das 14 pessoas que participaram, apenas 11 responderam o questionário. Os convidados poderiam participar da oficina através de seu celular ou computador. Além disso, o Moodle oferece compatibilidade com as duas plataformas.

Foi estipulado que a oficina tinha um tempo médio de 10 a 15 minutos de duração, porém os participantes não tinham a obrigação de finalizar antes ou depois deste prazo, levando em conta que todos têm uma maneira diferente de ler, aprender e responder.

Analisando o gráfico relacionado às respostas da pergunta sobre o sentimento ao realizar a oficina, percebeu-se que mais da metade dos participantes tiveram receio de realizar as atividades propostas por falta de domínio da plataforma Moodle. O gráfico é apresentado na Figura 4.
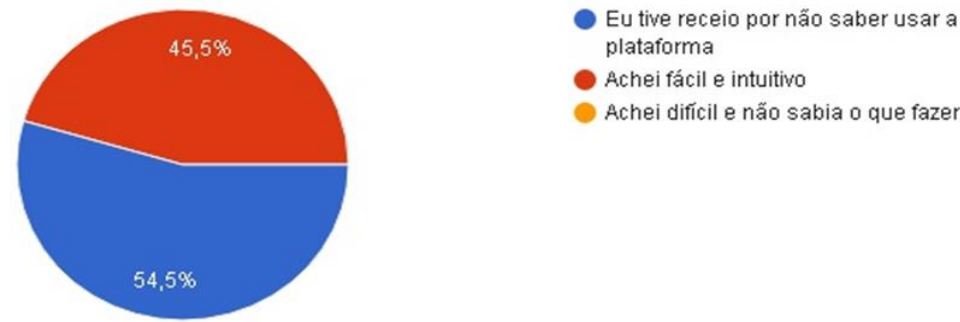

Figura 4. Sentimento durante a interação com a oficina

Diante disso, confirmou-se o pensamento de Esteban (2000, p. 4) quando afirma que "o medo do erro impede que o sujeito viva o processo de construção do conhecimento em sua intensidade, impedindo a ousadia, a busca do novo". O fato dos participantes não terem experiência prévia, explica o porquê deles terem receio por não saber usar a plataforma como mostra no gráfico da Figura 5.

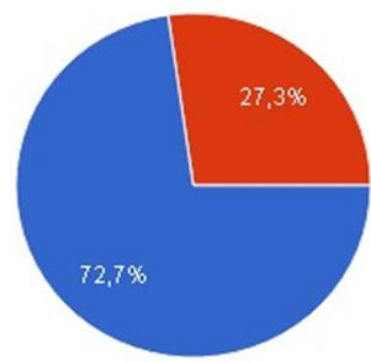

Não tive oportunidade

- Sim, já tive experiência

Figura 5. Experiências anteriores com metodologias de jogos fora do contexto de jogos 
VIII Congresso Brasileiro de Informática na Educação (CBIE 2019)

Anais do XXV Workshop de Informática na Escola (WIE 2019)

Dos que tinham experiência com metodologias de jogos, foi dado a oportunidade de falarem a respeito dessa experiência a partir da pergunta 9 ("Caso tenha respondido "Sim" na pergunta anterior, conte um pouco de como e onde você teve essa experiência"). Na Tabela 1 é apresentado os feedbacks obtidos.

Tabela 1. Respostas da pergunta 9 do questionário

\begin{tabular}{|l|l|}
\hline \multicolumn{1}{|c|}{ Pergunta } & \multicolumn{1}{|c|}{ Respostas } \\
\hline $\begin{array}{l}\text { P9 - Caso tenha } \\
\text { respondido "Sim" } \\
\text { na pergunta } \\
\text { anterior, conte um } \\
\text { pouco de como e } \\
\text { onde você teve } \\
\text { essa experiência. }\end{array}$ & $\begin{array}{l}\text { Ra escola em que estudava, utilizava a plataforma online do sistema } \\
\text { COCnsino. Depois de estudar determinado assunto, o aluno poderia } \\
\text { modo, avaliam o aprendizado. }\end{array}$ \\
\cline { 2 - 2 } & $\begin{array}{l}\text { R2 - Bem, na minha antiga escola havia um professor que utilizava a } \\
\text { gamificação, só que acho que ele não sabia que esse era o nome do que } \\
\text { ele dava um linha um sistema de recompensas no final do bimestre onde } \\
\text { eluno com maior nota. Isso nos motivava a estudar } \\
\text { e obter um melhor desempenho. }\end{array}$ \\
\cline { 2 - 2 } & $\begin{array}{l}\text { R3 - Durante o ensino fundamental II e ensino médio o colégio em que } \\
\text { estudava fazia uso do sistema COC, que em sua plataforma digital } \\
\text { utilizava da metodologia de jogos como feedback para o assunto } \\
\text { aprendido. }\end{array}$ \\
\hline
\end{tabular}

Pouco tempo depois de iniciar as atividades da oficina, três participantes concluíram antes do tempo estipulado, visto que apenas o vídeo da entrevista da atividade 3 possui a duração de 4 minutos e 46 segundos. Desta forma, pode-se considerar que estes participantes apresentaram certa resistência à execução "normal" das atividades. Quando questionados do porquê de terem finalizado a oficina tão rápido, eles responderam que estavam sem tempo.

Dos 11 participantes que responderam o questionário, 72,7\% têm o costume de jogar, dos que jogam, 62,5\% jogam de 10 à 30 minutos durante o dia e durante a semana jogam de 1 à 3 vezes.

Em relação ao sistema de recompensas de medalhas, 54,5\% dos participantes se sentiram recompensados, $27,3 \%$ se sentiram motivados, $9,1 \%$ se sentiram recompensado e motivado e $9,1 \%$ se sentiram indiferente. Desta forma, pode-se notar que houve comportamentos de engajamento em $90,9 \%$ dos participantes da oficina, como mostra o gráfico da Figura 6.

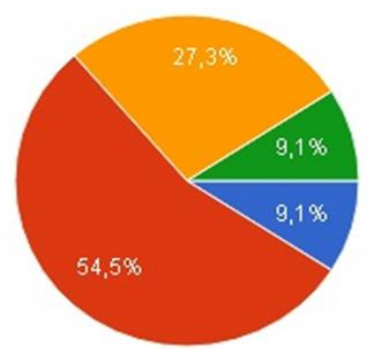

Indiferente

Recompensado

Motivado

Recompensado e Motivado

Figura 6. Sentimento ao receber medalhas ao finalizar cada atividade 
VIII Congresso Brasileiro de Informática na Educação (CBIE 2019)

Anais do XXV Workshop de Informática na Escola (WIE 2019)

Na pergunta 10 ("Você participaria de um curso técnico ou de graduação à distância que utiliza gamificação?") 63,6\% responderam que "talvez" participariam de um curso de graduação a distância que utiliza tais métodos. Os 27,3\% que responderam "Sim", tiveram a opção de responder a pergunta 11 ("Caso tenha respondido "Sim" na pergunta anterior, conte um pouco do porque você participaria de um curso à distância com gamificação"). Na Tabela 2 é apresenta as respostas obtidas dos usuários a respeito de se participariam de um curso com gamificação.

Tabela 2. Respostas da pergunta 11 do questionário

\begin{tabular}{|c|c|}
\hline Pergunta & Respostas \\
\hline \multirow{5}{*}{$\begin{array}{l}\text { P11 - Caso tenha } \\
\text { respondido "Sim" na } \\
\text { pergunta anterior, } \\
\text { conte um pouco do } \\
\text { porque você } \\
\text { participaria de um } \\
\text { curso à distância com } \\
\text { gamificação. }\end{array}$} & $\begin{array}{l}\text { R1 - Eu não participaria por causa da gamificação, ela seria um extra. } \\
\text { Eu participaria do curso por que me interessaria por ele, tipo 'curso de } \\
\text { primeiros socorros à distância' eu participaria por causa dos primeiros } \\
\text { socorros, não da gamificação. }\end{array}$ \\
\hline & $\begin{array}{l}\text { R2 - Apesar do receio com o ead, participaria por perceber a } \\
\text { gamificação como método efetivo e motivador para o aprendizado. }\end{array}$ \\
\hline & R3 - Pelo formato de jogo e recompensa. \\
\hline & $\begin{array}{l}\text { R4 - É estimulante, uma plataforma que traz recompensas em troca } \\
\text { de esforço! }\end{array}$ \\
\hline & R5 - Aparenta ser mais intuitivo, e interessante. \\
\hline
\end{tabular}

\section{Conclusão}

É notável que as tecnologias possuem um potencial na mediação do processo de ensinoaprendizagem. Com isso, este trabalho buscou apresentar a estratégia de gamificação como uma possibilidade de comportamentos de engajamento em estudantes numa plataforma de ensino a distância.

Visto o potencial que as estratégias de jogos aplicadas a métodos de ensino têm, elas podem trazer grandes resultados numa população de indivíduos que estudam através da internet, principalmente em cursos de EAD. Cursos que foram bem estruturados e que possuem recursos de interação, recompensa, materiais multimidiáticos, de feedback imediato e de progressão, têm um bom nível de satisfação de seus usuários. Ainda se destaca que em cursos mal estruturados e com uma metodologia pouco atrativa, muitas vezes, não despertam o interesse do estudante para a aprendizagem dos conceitos abordados, tornando-se um processo de ensino-aprendizagem mecânico, exaustivo e sem efeito.

Atualmente existem algumas alternativas de plataformas e recursos para poder desenvolver esses tipos de atividades, trazendo a possibilidade de gerar novos trabalhos deste tipo. Apesar da população deste trabalho ser reduzida, foram apresentados resultados já esperados para análise, podendo servir como recurso de estudo para futuras pesquisas.

Como trabalhos futuros, propõem-se o aprofundamento conceitual de gamificação, correção de algumas falhas teóricas e técnicas e, possivelmente, desenvolver uma nova plataforma gamificada. 
VIII Congresso Brasileiro de Informática na Educação (CBIE 2019)

Anais do XXV Workshop de Informática na Escola (WIE 2019)

\section{Referências}

ESTEBAN, M, T. (2000) "Exigências Democráticas/Exigências Pedagógicas: Avaliação." Vol 21, n. 148, Jan/Fev/Mar. Rio de Janeiro: Revista ABT.

FOGG, B.J.A (2009). "Behavior model for persuasive design." Proceedings of the 4th International Conference on Persuasive Technology. Claremont, California, p.26-29,

GNOMIO. (2019) Disponível em: https://www.gnomio.com/, Julho.

LIAW, S. (2008) "Investigating students perceived satisfaction, behavioral intention, and effectiveness of e-learning: a case study of the Blackboard system." Computers \& Education, v.51, n. 2, p.864-873.

MARTINS, Cristina; GIRAFFA, Lucia Maria M. (2015) “Gamificação nas práticas pedagógicas em tempos de cibercultura: proposta de elementos de jogos digitais em atividades gamificadas." XI Seminário SJEEC.

MOODLE. (2019) https://moodle.org, Julho.

MORAN, J.M. (2000) "Ensino e aprendizagem inovadores com tecnologias audiovisuais e telemáticas." In: MORAN, J. M.; MASETTO, M.T.; BEHRENS, M.A. Novas tecnologias e mediação pedagógica. São Paulo: Papirus.p.11-65.

NETTO, M. C. Gamificação com Moodle. 2015. (6m56s). https://www.youtube.com/watch?v=jwacPRZt4uI\&t=, Julho.

NETTO, Marinilse. (2014) “Aprendizagem na EAD, Mundo Digital e 'Gamification'." São Paulo: Pimenta Cultural. 300p.

PEREIRA, Alice Cybis; SCHMITT, Valdenise; DIAS, Maria Regina Alvares. (2007) "Ambientes Virtuais de Aprendizagem." In: PEREIRA, Alice T. Cybis. (orgs). AVA - Ambientes Virtuais de Aprendizagem em Diferentes Contextos. Rio de Janeiro: Editora Ciência Moderna Ltda.

ROQUE, A. S., GEISS, E. R., SANTOS, C. P., and SILVA, D. R. (2013). “Técnicas de gameficaçao em AVAs: um estudo de caso no ambiente virtual de aprendizagem Moodle". Encontro Anual de Tecnologia da Informação (EATI) e Semana Acadêmica de Tecnologia da Informação, 53-60.

SALAOFICIAL. "Gamificação na Educação." (2013) (4m42s). https://www.youtube.com/watch?v=-FoYdhcSZ6w\&t=, Julho.

SEIXAS, L. R., GOMES, A. S., MELO FILHO, I. J., and RODRIGUES, R. L. (2014). "Gamificaçao como estratégia no engajamento de estudantes do ensino fundamental". In Brazilian Symposium on Computers in Education (Simpósio Brasileiro de Informática na Educação-SBIE) (Vol. 25, No. 1, p. 559).

SHELDON, Lee. (2012) "The Multiplayer Classroom: Designing Coursework as a Game.” Boston, MA: Cengage Learning.

VIANNA, Ysmar; MEDINA, Bruno; TANAKA, Samara; VIANNA, Maurício. (2013) "Gamification, Inc. - Como reinventar empresas a partir de jogos." MJV Press. 